\title{
Contributions to the Development of a Crop Growth Model for Assessing Grass-Legume Interactions
}

\author{
Daniel DUNEA ${ }^{1}$, Niculae DINCĂ ${ }^{2 *}$ \\ ${ }^{1}$ Valahia University of Targoviste, Romania. \\ ${ }^{2}$ University of Agronomic Sciences and Veterinary Medicine Bucharest, Romania. \\ *Corresponding author: nicudinca@yahoo.com \\ Bulletin USAMV series Agriculture 72(2)/2015 \\ Print ISSN 1843-5246; Electronic ISSN 1843-5386 \\ DOI 10.15835/buasvmcn-agr: 11611
}

\begin{abstract}
Crop growth and development, as well as ecophysiological assessments, can be obtained directly from field experiments, but only a finite set of variables can be studied in this way. A model used to simulate the biological efficiency cycle considering the soil-plant-climate system is essential in assessing the associated fluctuations due to year-to-year variability of the climate, or for testing the effect of various cropping practices. Models that simulate crop growth were developed, on one hand, to predict the yields, and on the other hand to analyze the impacts of agricultural practices on environment and productivity. The aims of this study were to develop a crop simulation model, coupled with experimental work on phenotypic and physiological mechanisms and their interactions in binary associations of perennial legumes and grasses. A logical flow diagram to conceive and interact for prototyping was built. Experimental data comprising crop growth values required for simulation were implemented as variables in each specific module. The diagrammatic model helped to assess the components of the LabVIEW software application as state variables, auxiliary variables, processes and parameters. At individual level, interspecific competition capacity depends on the deployment efficiency of morphological organs specialized to gain resources. Crop models could use the added structural detail by incorporating detailed routines of light interception and resource allocation to respond to spatial variations of local conditions that result from species growth within mixed canopy.
\end{abstract}

Keywords: crop simulation, interspecific competition, mixed canopy, light use efficiency.

\section{INTRODUCTION}

The forage production is designed as an information and decision system, which includes all means of production, techniques and processes that ensure the link between the food resources (cropping systems) and feed requirements (animal breeding systems) using feeding systems (nutrition). Consequently, all three components of the forage production (cropping system, feeding system and animals maintenance system) are interdependent and only the fully approach enables the development of viable solutions that are capable of ensuring its functionality, practical efficiency and resilience within the limits of ecological equilibrium (Motcă et al., 2005). For a long time, the performance of a cropping system, including grasslands, was usually judged only based on the yield, i.e. the amount of supplied nutrients (Dale et al., 2013); when the qualitative attributes of resources were taken into account, they were quite summarily and unilaterally treated.

Cropping systems of perennial grasses and legumes are an essential component of agricultural ecosystems in hilly areas and plains (Vîntu et al., 2004). In the context of sustainable agriculture, the utilization value of these crops acquires a new dimension being evaluated not only according to strict agricultural and economic indicators, as well as according to environmental indicators such 
as environmental quality, landscape quality, the effect of ecological compensation etc. (Dunea and Dincă, 2014).

Ecophysiological modeling applied to forage crops is a supportive technique to quantify the dry matter accumulation in optimal cropping conditions (Dunea et al., 2015). Ecophysiological deterministic approach explains the processes of plants' growth and development through the assimilation (photosynthesis) and desassimilation (respiration). Sensitivity analysis of the model enables the assessment of mechanisms and interactions that occur in the real conditions of cropping system.

In the last decades, many simulation models of growth and development processes occurring in agricultural or natural ecosystems have been developed by integrating interdisciplinary knowledge in a unified framework that enabled the analysis of ecophysiological mechanisms under various ecological conditions. The approach is characterized by the following words: systems - a limited part of the real world, models - a diagrammatic representation of the system, and simulation - the development of mathematical models and sensitivity analysis of the model in relation to the evolution of the real system.

Penning de Vries and van Laar (1982) introduced a classification based on the state variable approach for modelling agricultural production systems using four production situations:

1. Potential production without water and nutrients limitations,

2. Crop growth is limited by water stress in various phenophases,

3. Crop growth is limited by water stress and nitrogen limitations,

4. Crop growth is limited by the shortage of phosphorus and potassium - complex situation.

The effect of limiting growth factors such as diseases, pests, weeds must also be included to quantify and simulate the real cropping conditions. Specific models were developed and fully evaluated for the first two production situations. Models that considered the third situation encountered difficulties regarding the nitrogen circuit simulation in the soil and its uptake by plants (Kropff and van Laar, 1993). Models based on the fourth situation are simple and without ecophysiological deterministic approaches, because the processes involved are too complex. Generally, most of the models are applicable to monocultures or pure crops and the morphological characteristics of species required for optimizing simulation procedures concerning the mechanisms of interspecific competition are missing from their structure.

The current deterministic models that estimate yield and other growth parameters have proven their versatility and efficiency in simulating crop growth and development of various species. Description of these models in the literature (Metselaar, 1999) is often a combination of a formal language (mathematical equations) and a descriptive language (English language text). The most representative models related to the current approach are summarized as follows:

- $\quad$ SUCROS 87 is applicable to annual monocultures and uses daily data inputs simulating the accumulation of dry matter in the morphological organs of the plant, resulting from various physiological processes influenced by radiative and advective factors: assimilation, respiration, growth and maintenance, senescence and biomass partitioning (Spitters, 1986; Metselaar, 1999).

- LINGRA is a model used to simulate the productivity of perennial ryegrass (Lolium perenne L.) grasslands in Europe. The key processes are simulated using light utilization, leaf formation and elongation, tillering and partitioning of carbon compounds. This model was validated after experiments conducted in 35 relevant European locations. Mean error between observed and predicted values was $14 \%$ for irrigated, respectively $19 \%$ for non-irrigated grasslands (Schapendonk et al., 1998).

- INTERCOM (Kropff and van Laar, 1993) is applicable to intercropping systems (polycrops) and enables the analysis of complex interactions between plant species in terms of competition for light, water and nitrogen. Furthermore, it simulates the growth under the influence of interspecific competition based on the following components: phenological development, morphological development (plant height and leaf area index), dry matter accumulation, dry matter allocation in plant organs and evapotranspiration.

- CERES (Crop Environment REsource Synthesis) are a group of models that simulate the daily evolution of plant growth under the impact of 
various irrigation schemes, and capture/leaching of nitrogen e.g. CERES Maize, CERES Sorghum etc.

- $\quad$ CROPWAT is a program that uses the FAO Penman-Monteith methods (1992) for calculating the reference evapotranspiration of a crop. The estimatesare used to assess the water requirements and calculation of norms for irrigation. Calculations are suitable for 30 cultivated species. Each species is defined by file name, sowing date and land cover (0-100\%). Evapotranspiration estimation is based on monthly data, which are integrated into daily values.

- $\quad$ GROWIT is a model designed to simulate the growth of clover species in pure stands or in mixture with accompanying species (Smith and Loewer, 1985).

Monitoring of ecophysiological processes that occur in intensive forage production systems requires an integrated approach by using $a$ model to estimate the growth and development of heterogeneous canopies to establish the boundaries and context of the mixed cropping systems. The complexity relies in its numerous technological and management operations conditioned by the ecological factors with the final aim to provide useful information for farmers. At this level, the information must be concise and explicit leading to the optimization of the cropping system and related investments (crop inputs).

The paper aims to characterize the physiological, phenological and morphological mechanisms that determine the interspecific competition or mutual cooperation within grasslegume mixed canopies and to include them in a logical flow structure that can be integrated in a software application for simulation of the crop growth of binary legume-grass mixtures under various weather conditions.

\section{MATERIALS AND METHODS}

A reliable model provides objective and quantitative extrapolations of information in space and time derived from past research and trial experiments. The model's validation and its predictive abilities depend on the integration of the real-life processes occurring in legume-grass systems. A logical flow diagram was developed to conceive the kernel prototype. Interactive prototyping refers to the process of matching the presentation and capabilities of the software application to the requirements of potential users. Experimental data comprising crop growth values of several common grass-legume mixtures required for simulation were implemented as variables in each specific module.

Actions to take and to follow were extracted from an integrative survey of the studied forage systems to fulfill the specific objectives of the software application called SimClover. The diagrammatic model supported the structuring of system's components as state variables, auxiliary variables, processes, and intrinsic parameters.

In a crop canopy, a complex process of energy transfer occurs and is characterized by several individual components such as net solar radiation, sensible heat flux between plants and atmosphere, heat flux between the soil and plants, evapotranspiration and solar radiation stored as photochemical energy. A complex approach to the growth and development of canopy was considered by quantifying the radiative-advective components as well as other factors that influence the crop status (e.g. air humidity, soil moisture, wind speed, dew point, etc.) compared to the simple energetic models.

Potential evapotranspiration (PET) is a complex index that describes the conceptual processes of soil water losses in atmosphere through evaporation and transpiration from the canopies depending on the plant, land cover, climatic conditions, and soil characteristics. A series of measurements used as inputs into the model that depend on the complexity of the equations, the estimation period, and the accuracy of results were required to assess this variable (Fig. 1).

Developing a reliable computerized environment for simulation and retrospective dynamic analysis of eco-physiological processes in binary grass-legume mixtures required a MBP (Model Builder Protocol). The necessary steps were as follows:

1. Establishing of clear simulation objectives;

2. Design of diagrammatic models and logical schemes to allow the conceiving of the mechanistic model;

3. Restrictions of objectives based on identified limits of known elements;

4. Specifications and features of the model were completed by eliminating, simplifying, or combining processes; 
5. Building - checking - calibrating - validating testing using sensitivity analysis;

6. Simulation experiments (to improve the subroutines of the model).

LabVIEW, a graphical programming environment from National Instruments was used to develop the software application and proved to be a versatile environment for the software application design, data acquisition, analysis, and presentation in ecophysiological modeling applications.

Eco-physiological parameters required for modeling the interactions between legume species and perennial grasses.

The following datasets were necessary to develop a simulation model for growth and development of associated species in a mixed grass-legume canopy:

1. Data concerning the characteristics of $\mathrm{CO}_{2}$ assimilation (initial light use efficiency, assimilation in the presence of luminescent saturation, effect of temperature, relative humidity of air, leaf age and light extinction coefficient);

2. Data concerning the efficiency of carbohydrates conversion produced in the process of dry matter assimilation for structural elements and carbohydrates required for maintenance processes;

3. Data concerning the partitioning of newly formed dry matter in various morphological components during the growth season;

4. Data concerning the dynamics of leaf area growth (e.g. specific leaf area, leaf lifespan etc.);

5. Data concerning the crop phenology (the crop growth is expressed in the model as phenophase development stage having preset values: 0 emergence, 1 flowering and 2 maturity).

\section{RESULTS AND DISCUSSION}

Plant communities are aggregations of species entities that compete within three-dimensional space to acquire vital resources (light, water and nutrients). Complex ecophysiological mechanisms exist between resources capture and plant responses, which engender modifications of canopy dynamics, and pattern of root development. At individual level, competitiveness depends on the deployment efficiency of morphological organs specialized to gain resources (Dunea et al., 2015). Crop models could use the added structural detail to assess the spatial variations in local conditions,

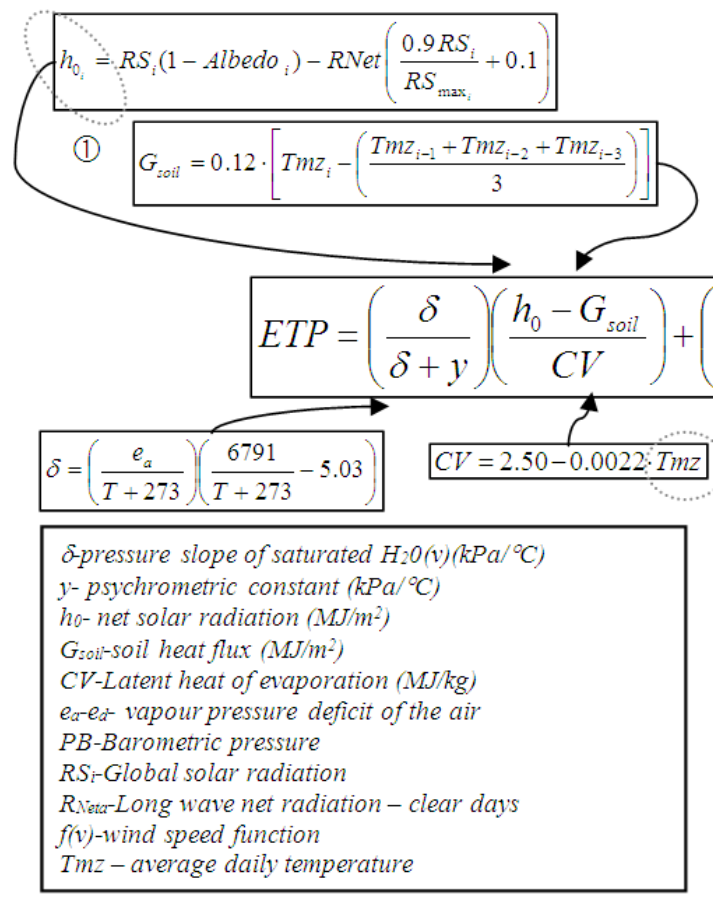

\section{PENMAN-MONTEITH}

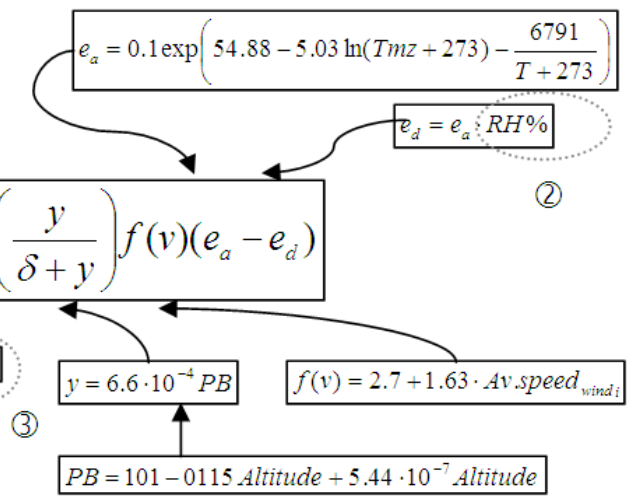

HARGREAVES

$E T P=\lambda\left(\frac{R S_{\max }}{C V}\right) \cdot(T m z+17.8) \cdot\left(T_{\max }-T_{\min }\right)^{0.6}$
$\lambda \in(0.0023,0.0032)$

Fig. 1. Algorithms for estimating the potential evapotranspiration (PET): (1) Penman-Monteith and (2) Hargreaves integrated in the SimClover simulation model of crop growth in mixed grass-legume canopies 
which result from plant growth, by incorporating detailed models of light interception and allocation of resources.

Assigning values for the model parameters was an important step to perform qualitative analyzes that allowed the comparison between modeled and expected phenotypic expressions of the species. The evaluation of parameters was the research component and was determined by experiments, using a part of the model or its full utilization. Establishing a connection between canopy architecture and the eco-physiological model was possible using measurements of the sward structure (Laca and Lemaire, 2000). Such measurements provided mechanistic explanations of eco-physiological processes i.e. growth rate, photosynthetic active radiation (PAR) interception, tillering, leaf life span, susceptibility to the attack of phytopathogens etc.

The developed model included not only leaf area index, but also the light extinction coefficient that gave a better estimate of the amount of absorbed PAR in canopy. The height of assimilation areas, the foliar architecture, leaf area density, reflection coefficient, and extinction coefficient were key elements to characterize the light interception process and the light use efficiency of the species.

Grasses may intercept virtually all (95\%) radiation at LAI 6 to 9, whereas temperate legumes will do so at LAI 2.5 to 4 (Pearson and Ison, 1987). In general, net photosynthesis of legumes increases linearly with LAI up to 3.5 and declines at higher LAI, independent of cultivar or sowing density (Joggi et al., 1983). The absorption efficiency of light becomes constant between LAI of 3.5-6.5, and the canopy reflectance diminishes with leaf area increment. The light extinction coefficient $(k)$ varies with ELADP and sun azimuth.

When a LAI of 4 is reached, most forage species attain maximum growth in optimal conditions without limitations. Higher LAI values do not correlate with substantial increase of yields, and the forage quality declines. Very high leaf areas do not give additional increases in production because basal leaves are shaded, old, or photosynthetically inefficient (Smith et al., 1986).

A simulation model can be characterized by a diagrammatic structure. The proposed model quantifies the influence of microclimate and canopy architecture of binary legume-grass mixtures (Fig.
2). Description of the PAR distribution transects within the canopy provides information regarding the patterns of the leaf dispersion randomness in mixed grass-legume canopies.

The flowchart of the model presents the information flow between the following subcomponents:

The architecture of mixed canopy is the resultant of aboveground and root structures of the component species (legumes and grasses), while the spatial arrangement refers to the percentage of participation in the association of plant species. Based on the field experiments results, it was observed that this percentage varies during the growth cycle due to interspecific competition mechanisms that occur because of the varying concurrence capacity of the species. The initial value is regarded as the seed rate of component species at crop establishment (e.g. $50 / 50$ or $25 / 75$ ).

The capture of resources (light, water, nutrients) depends on aboveground structure and root system, a significant influence having the available solar radiation for both species. At this level, the canopy microclimate is important due to its advective component, and the fluxes of water vapors and heat modify the initial microclimate conditions following the intensity of light interception process.

The species response in the mixed canopy is the result of captured resources utilization based on physiological traits of component species. The response is actually represented by the increase of biomass accumulation in species. Depending on the development phase, the model simulates the partitioning of dry matter in morphological components. The growth rate is strongly dependent on temperature. Important simulated indicators are the foliage properties (LAI, LWR, LAR, etc.), the height of the shoots, foliage density, tillering etc., which modify the canopy structure. Vertical and horizontal locations of assimilatory areas (mainly leaves) describe the leaf area density (LAD), which is a spatial distribution parameter used in multilayer mixed canopy models for calculating light profiles and absorption of light by species (Kropff and van Laar, 1993).

A modular structure was developed as follows:

- module for bivariate regression tests between variables is a useful tool for identifying preliminary statistical relationships between the 
variables selected by the user. The module allows the testing of linear, exponential or polynomial functions displaying the significance of MSE (mean square error) with graphical visualization of simulated versus observed data. Predicted numerical values are also displayed. Possible correlations can be tested i.e. between dry matter and PAR, LAI and temperature, vegetation height and temperature, same parameter of both associated species etc.

- $\quad$ module for potential evapotranspiration assessment was developed using the PenmanMonteith algorithm as well as Hargreaves method to verify the results (Fig. 1). The inputs required are collected from specific sensors i.e. net radiometer, relative humidity, soil moisture, and soil and air temperatures (Fig. 3).

- module for dynamic modeling of light interception and absorption in the canopy was built considering that interception of solar irradiance by a crop canopy results in both quantitative and qualitative changes in the photosynthetic photon flux density (PPFD), which have impact on intraspecific and interspecific competitions. The arrangement and orientation of the leaves within the canopy influences the photon flux that is absorbed by the canopy and the amount of photons per unit sunlit leaf area. In the case of plants' associations (cultivated speciesweeds, legume-grass mixtures, polycrops or

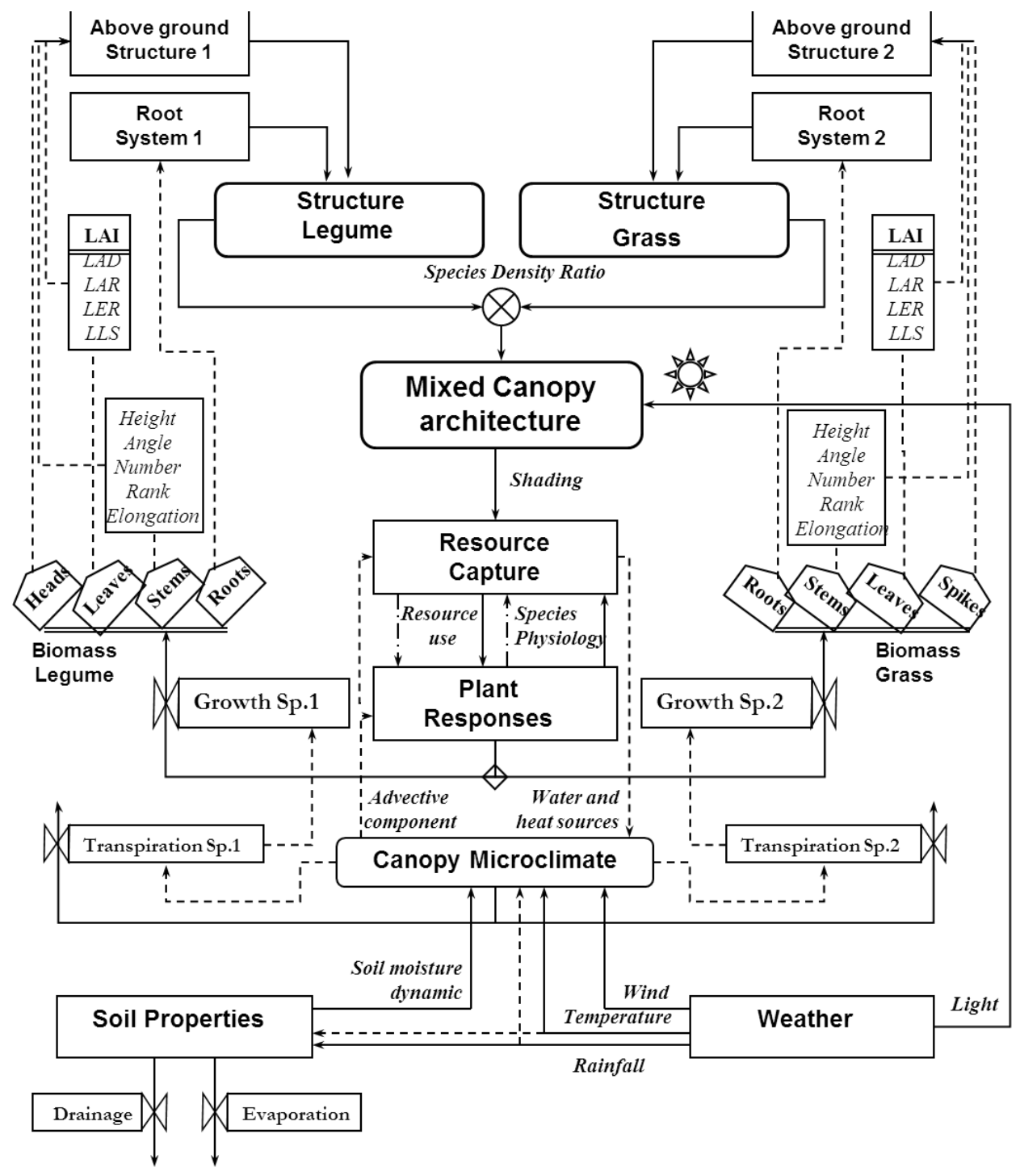

Fig. 2. A flow chart for legume-grass mixtures used to develop a dynamic model (LAI - leaf area index; LAD - leaf area density; LAR - leaf area ratio; LER - leaf elongation rate; LLS - leaf life span) 
phytosociological associations), interception of light in mixed canopies is mainly influenced by the LAI, the leaf area density and absorption characteristics of each component species. Light absorption characteristics of species depend on optical properties, thickness and goniometric distribution of leaves. This distribution determines the amount of radiation absorbed per unit of leaf area. Planophile leaf species (e.g. legumes) captures light more efficiently than erectophile canopies (e.g. perennial grasses). However, canopy photosynthetic efficiency will be significantly higher in erectophile than in planophile canopies at similar PPFD absorption rates. It is estimated that from the total quantity of light on a leaf (100\%), 1.5 to $3.0 \%$ is used in the process of photosynthesis, and the rest is reflected, is passing through the leaf, is lost as heat or is used in the transpiration process as latent heat of vaporization. The required inputs in this module are as follows: the latitude of site, the growth cycle of perennial crop in the vegetation season, day number of the growth cycle on which sunshine duration is estimated, and together with the solar constant provide the daily global radiation amount at the Earth's surface in the

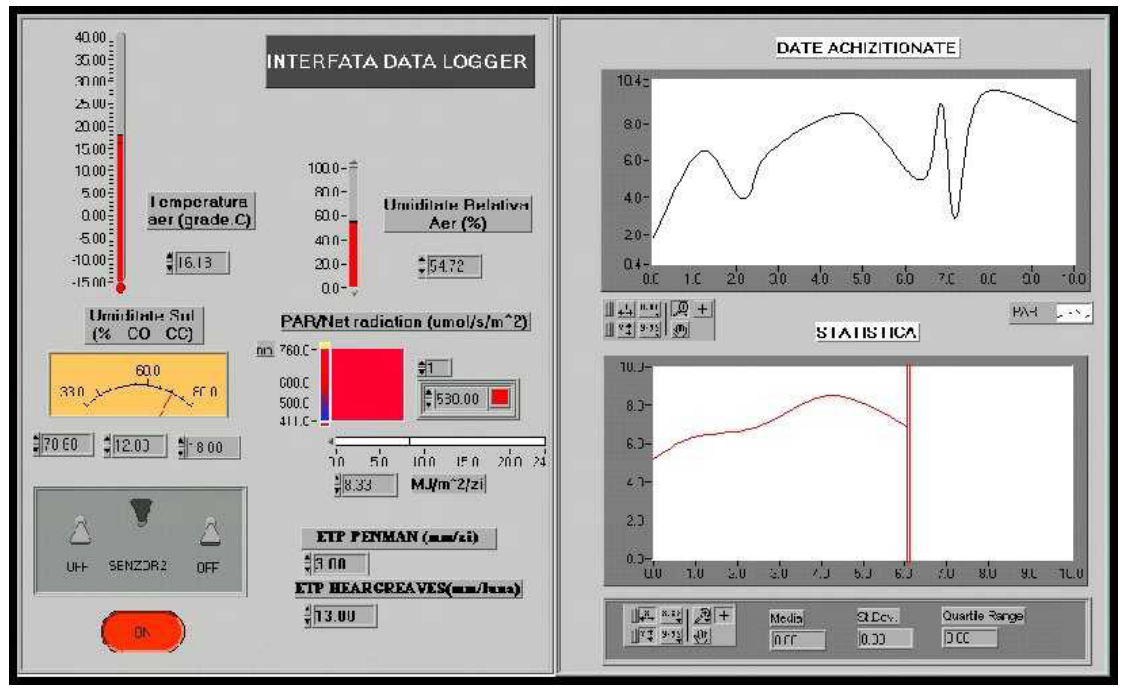

Fig. 3. Interface for microclimate data visualization/acquisition (temperature, PAR, relative air humidity, soil moisture, etc.) collected from the crop canopy that provides PET estimations

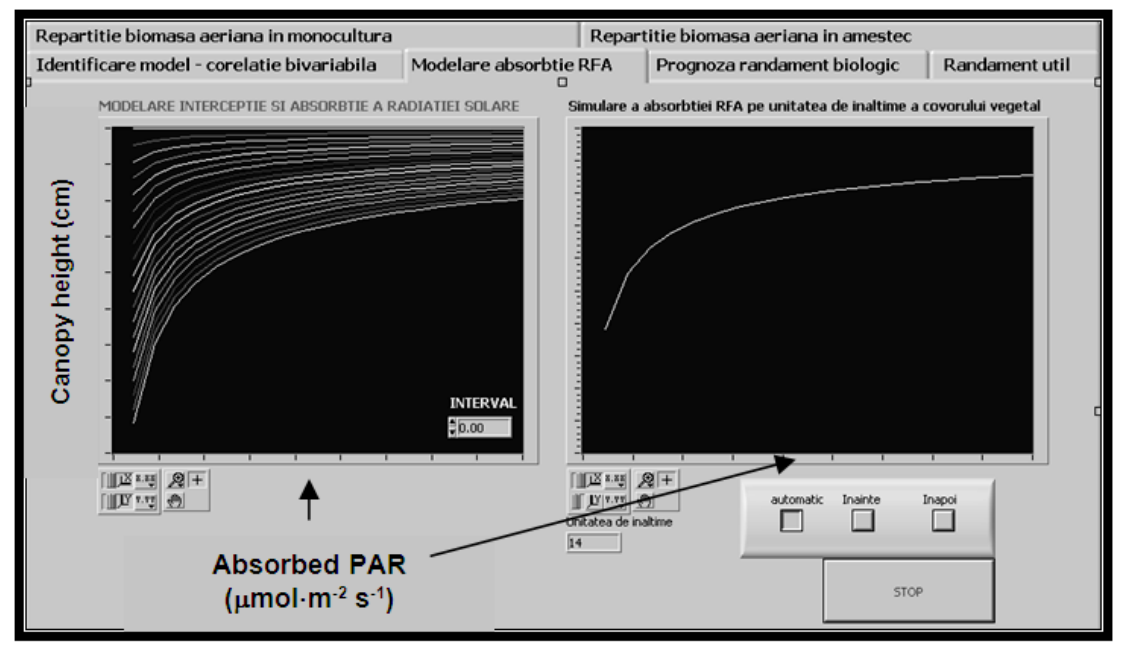

Fig. 4. Interface of the dynamic modeling module for light interception and absorption $\left(\mathrm{PAR}_{\mathrm{a}}\right)$ in homogeneous or mixed canopies 
absence of atmosphere. The result is corroborated with the solar radiation measured data to obtain the atmospheric transmission, from which the total flows of direct and diffuse radiations are estimated. Integration of daytime enables the calculation of instant light flows values. Values are multiplied with 0.48 resulting the direct and diffuse PAR estimates (Fig. 4).

Figure 5 presents an example of SimClover software application outputs such as the relative PAR per unit canopy height $(\mathrm{cm})$ for both species that forms the mixed canopy as well as their fitted exponential trend-lines of radiative fluxes ratios in function of LAI: intercepted PAR/total PAR; absorbed PAR/total PAR; reflected PAR/total PAR.

- module for estimation of net yield was developed using the quantitative analytical framework (Goudriaan, 1977; Varlet-Grancher et al., 1989; Dunea, 2006) from which the most important variables are presented below (Eq. 1 and 2):

Absolute Growth Rate (AGR):

$$
\begin{aligned}
A G R=\frac{1}{A} \cdot \frac{d W}{d t}= & \left(\frac{L}{A}\right) \cdot\left(\frac{d W}{L d t}\right) \quad\left[\mathrm{kg} \cdot \mathrm{m}^{-2} \cdot d a y^{-1}\right] \\
& \downarrow \quad \downarrow \\
& \text { LAI } \quad \text { NAR }
\end{aligned}
$$

where:

$\mathrm{W}$ - dry matter accumulation $\left[\mathrm{kg} \mathrm{m}^{-2}\right]$;

$\mathrm{LAI}=\mathrm{L} / \mathrm{A}$ - leaf area index $\left[\mathrm{m}^{2}\right.$ leaves $/ \mathrm{m}^{2}$ soil $]$;

RAN - net assimilation rate $\left[\mathrm{kg} \times \mathrm{m}^{-2}\right.$ leaves $\times$ day $\left.^{-1}\right]$. the relationship between AGR and incident solar radiation $\mathrm{I}_{0}$ :

$$
N\left(\frac{d W}{d t}\right)=\left(I_{0}\right) \cdot\left(\frac{N J}{I_{0}}\right) \cdot\left(\frac{1}{J}\right) \cdot\left(\frac{d W}{d t}\right)
$$

where:

$\mathrm{I}_{0}$ - incident solar radiation $\left[\mathrm{W} \times \mathrm{m}^{-2}\right.$ or $\left.\mathrm{MJ} \times \mathrm{m}^{-2}\right]$;

$\mathrm{J}$ - intercepted radiation by plants $\left[\mathrm{W} \times \mathrm{m}^{-2}\right.$ or $\left.\mathrm{MJ} \times \mathrm{m}^{-2}\right]$;

$\mathrm{N}$ - plant density [number of plants $/ \mathrm{m}^{2}$ ]

\section{CONCLUSION}

The developed software tool allows the analysis of complex interactions between perennial legume and grass species regarding the interspecific competition for light and biomass partitioning in morphological components. Parameterization and calibration steps are further required using data from experimental trials to increase the generalization capabilities of the model. The reliability of the model for simulation of forage production is significantly correlated to a coherent approach to evaluate interception and absorption of solar radiation in heterogeneous canopies. The program has flexible menus that facilitate the management of files and graphical presentations of inputs (microclimate, spatial arrangement, plant density, latitude of site, production cycle, day number of the growth cycle etc.) and modeling results (light use of
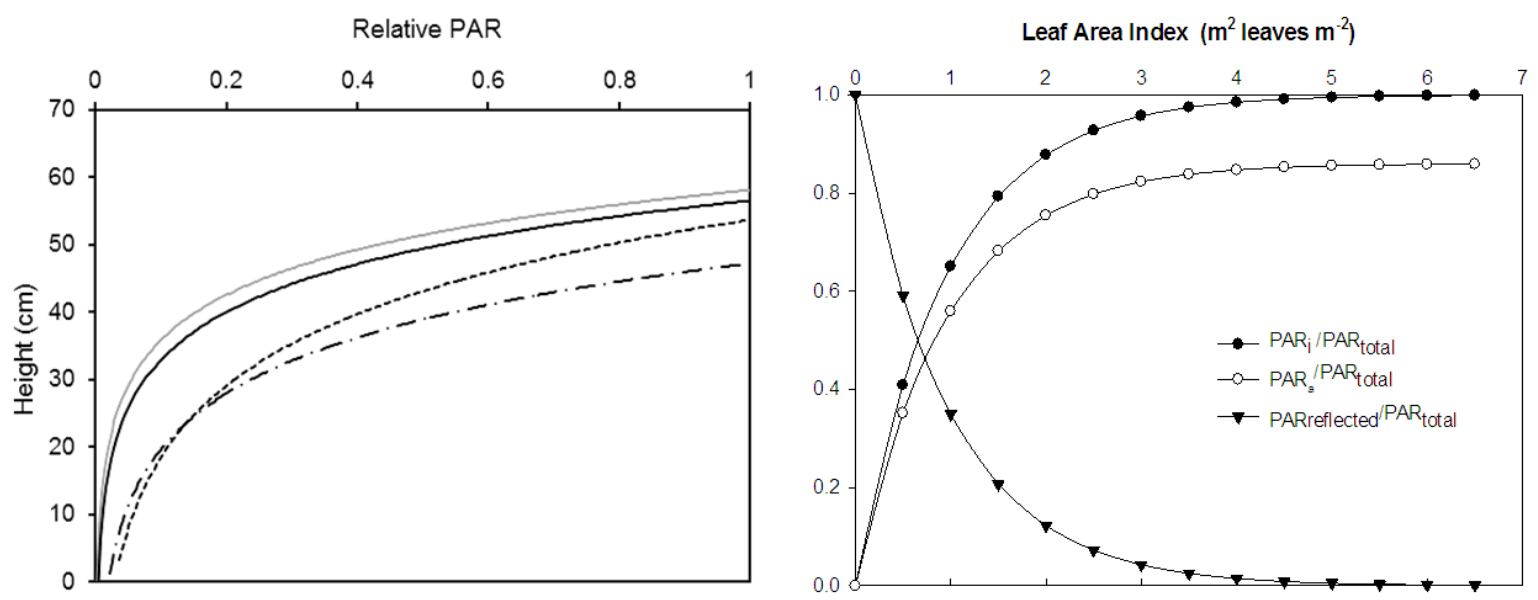

Fig. 5. Example of SimClover outputs: (1) Relative PAR per unit canopy height (cm) for accompanying grass - LAI 3.21 \pm 0.9 (dotted lines) and legume - LAI $5.6 \pm 1.4$ (full lines) and (2) their fitted exponential trend-lines of radiative parameters ratios in function of LAI: Intercepted PAR/Total PAR; Absorbed PAR/Total PAR; Reflected PAR/Total PAR 
species in the mixture, soil moisture deficit, water requirements etc.).

The modeling procedures are based on microclimate and agro-meteorological data and files containing radiation-thermal and rainfall regimes. Useful outcomes are expected in establishing the cropping design setup, because the software application is able to extrapolate the model results at farm-scale level. A posteriori evaluation of acquired performances contributes to revise initial elements (objectives, managerial actions, decisions, and inputs) towards the projected stability and sustainability, which will optimize the legume-grass cropping system. Rigor must be undertaken based on an efficient agronomic diagnose, when technical feasibility (grassland operations) and resulted performances are analyzed to characterize the persistence of species in specific eco-climatic conditions. Consequences for overall productivity and quality of the fodder should be known for the selection of the most appropriate species and cultivar to be added to the mixed cropping system. The software application provides support by simulating dry matter accumulation in various scenarios.

\section{REFERENCES}

1. Dale LM, Thewis A, Rotar I, Boudry C, Păcurar FS, Lecler B, Agneessens R, Dardenne P, Baeten V (2013). Fertilisation effects on the chemical composition and in vitro organic matter digestibility of semi-natural meadows as predicted by NIR spectrometry, Not Bot Horti Agrobo 41(1): 58-64.

2. Dunea D, Neagu Frăsin LBN, Dincă N (2015). Ecophysiological responses of white clover- hybrid ryegrass mixture to foliar fertilisation, Not Bot Horti Agrobo 43 (1): 173-178.

3. Dunea D, Dincă N (2014). Improving land utilization using intensive grass-clover mixtures in forage production systems, Romanian Agricultural Research 31: 1-11.

4. Dunea D (2006). Solar radiation bioconversion of red clover (Trifolium pratense L.) in Târgoviște Plain, Ph.D. Thesis, University of Agronomic Sciences and Veterinary Medicine Bucharest.
5. Goudriaan J (1977). Crop Micrometeorology: A Simulation Study, Centre for Agricultural Publication Documentation, Wageningen, Netherlands.

6. Joggi D, Hofer V, Nősberger J (1983). Leaf area index, canopy structure and photosynthesis of red clover (Trifolium pratense L.), Plant, Cell, Envir. 6: 611-616.

7. Kropff MJ, van Laar HH (1993). Modelling Crop-Weed Interactions, $\mathrm{CAB}$ International, Wallingford.

8. Laca EA, Lemaire G (2000). Measuring sward structure, In: t'Mannetje L. and Jones R.M. (eds.) Field and laboratory methods for grassland and animal production research, CAB International, Wallingford: 103-122.

9. Motcă Gh (2005). Improving utilization value of perennial grasses and legumes in the context of sustainable development of agriculture in Romanian Plain (in Romanian), CNCSIS Grant 559 Research Report, Revista de Politica Științei şi Scientometrie, Special Number.

10. Metselaar K (1999). Auditing predictive models: a case study in crop growth, Ph.D. Thesis, Wageningen Agricultural University.

11. Pearson CJ, Ison RL (1987). Agronomy of Grassland Systems, Cambridge University Press, Cambridge.

12. Penning de Vries FWT, van Laar HH (eds) (1982). Simulation of plant growth and crop production, Simulation Monographs, Pudoc, Wageningen.

13. Schapendonk AHCM, Stol W, van Kraalingen DWG, Bouman BAM (1998). LINGRA, a sink/source model to stimulate grassland productivity in Europe, European Journal of Agronomy 9: 87-100.

14. Smith B, Leung P, Love G (1986). Intensive Grazing Management: Forage, Animals, Man, Profits, The Graizers Hui, Kamuela, Hawaii.

15. Smith EM, Loewer OJ (1985). Computer simulation of management and utilization systems, In N.L. Taylor (ed.), Clover Science and Technology. ASA Monog. 25: 355-364. Madison, WI.

16. Spitters CJT (1986). Separating the diffuse and direct component of global radiation and its implications for modeling canopy photosynthesis. Part II. Calculations of canopy photosynthesis, Agricultural and Forest Meteorology 38: 231-42.

17. Varlet-Grancher C, Gosse G, Chartier M, Sinoquet H, Bonhomme R, Allirand JM (1989). Mise au point: rayonnement solaire absorbé ou intercepté par un couvert vegetal, Elsevier/INRA: 419-439.

18. Vîntu V, Moisuc Al, Motcă Gh, Rotar I (2004). Grasslands and forage crops (in Romanian), Editura Ion Ionescu de la Brad, Iasi. 